\title{
POLARIZATION MIGRATION OF THREE-COMPONENT REFLECTED WAVES UNDER SMALL MIGRATION APERTURE CONDITION
}

\author{
Bo WANG ${ }^{1)}$, Shengdong LIU ${ }^{1) *}$, Fubao ZHOU ${ }^{2)}$, Tuo LU ${ }^{1)}$, \\ Lanying HUANG ${ }^{1)}$ and Yingjie GAO ${ }^{3)}$ \\ ${ }^{1)}$ State Key laboratory of deep geomechanics \& underground engineering and School of Resource and Earth Science, \\ China University of Mining and Technology, Xuzhou, 221116, P. R. China \\ ${ }^{2}$ School of Safety Engineering, China University of Mining and Technology, Xuzhou, 221116, P. R. China \\ ${ }^{3)}$ Key Laboratory of the Earth's Deep Interior, Institute of Geology and Geophysics, Chinese Academy of Sciences, \\ Beijing, 100088, P. R. China \\ *Corresponding author's e-mail: wbsyes@126.com
}

\section{ARTICLE INFO}

Article history

Received 30 June 2015

Accepted 2 October 2015

Available online 22 October 2015

Keywords:

Roadway

Faults

Artifacts

Reflected waves

Polarization migration

\begin{abstract}
Faults pose a great threat to the safety of tunnel and roadway construction. Expanding the scientific community's understanding of advanced fault detection through research is therefore of critical importance. However, narrow roadway space often restricts sources and receivers positioning, resulting in small migration aperture problems during advanced migration imaging. The resulting artifacts make it impossible to analyze occurrence parameters of faults, such as dip and trend. In this paper, we introduce a solution to this problem with three-component (hereafter called " 3 C") reflected signals. The solution can be roughly divided into three steps. First, we use a covariance matrix to calculate the principal polarization direction, which indicates the principal energy propagating direction of reflected waves. A factor is introduced to represent the principal polarization direction. Second, we establish a weighted function of the factor and apply the function in migration computation. Finally, we put forward a polarization migration imaging technique to eliminate the artifact so that we can accurately predict occurrence parameters. It has been proven that polarization migration is an efficient way to achieve advanced imaging of faults under small migration aperture condition through numerical simulations, water sink model experiments, and roadway field experiments.
\end{abstract}

\section{INTRODUCTION}

The security of tunnel and roadway construction is affected by hazard sources, such as fault fracture zones, water-conducting structures, and gas-rich zones (Kabiesz, 2006; Esaki et al., 2008; Busygin and Nikulin, 2013). These sources are usually closely associated with geological structures, especially faults (Islam and Shinjo, 2009; Li et al., 2011; Zhang and Lan, 2013). Currently, the advanced prediction of faults is a popular topic (Essen et al., 2007; Bohlen et al., 2007; Wang et al., 2014). Common geophysical methods of seismic wave detection in tunnels include seismic negative apparent velocity method (Zeng, 1994), Tunnel Seismic Prediction (Sattel et al., 1996), Horizontal Seismic Profiling (Inazaki et al., 1999), Integrated Seismic Imaging System (Borm et al., 2001), Tunnel Seismic Tomography (Zhao et al., 2006), Reflected-Wave Tunnel Seismic Prediction (Shen et al., 2008), Tunnel Geology Prediction (Liu and Mei, 2011), True Reflection Tomography (Wang et al., 2011; Cheng et al., 2014). Those methods have been applied widely, each marking a technological achievement or scientific breakthrough but they do not achieve fine imaging attributable to the limited aperture. Lüth et al. (2005) applied Fresnel volume migration to synthetic VSP data and to real data acquired in a tunnel, and the conclusion show that the migration results in enhanced images of reflectors compared to standard depth migration.

However, the space of coal mine roadway is strongly limited, the width of coal mine roadway is only $3 \mathrm{~m} \sim 5 \mathrm{~m}$ which is below tunnel width. Advanced detection in the roadway is limited by narrow space, and small migration apertures (seen in Figure 1a) will lead to artifact that disrupt imaging. The two images exist in a $2 \mathrm{D}$ migration section symmetrically (Chang et al., 2006; Gong et al., 2010), as seen in Figure 1b, which causes misleading geological forecasts and thus affects excavation efficiency and safety.

To solve the problem, we study polarization migration imaging with the principal polarization direction parameters in polarization analysis on the basis of 3C seismic reflected signals. In this paper, we calculate the principal polarization direction and introduce a factor of the principal energy propagating direction of reflected waves, establish a weighted function and apply the function in migration computation. Finally, we put forward the migration to numerical simulations, water sink model experiments, and roadway field experiments. Three experiments show that polarization migration eliminates the fault artifact by PP reflection. 

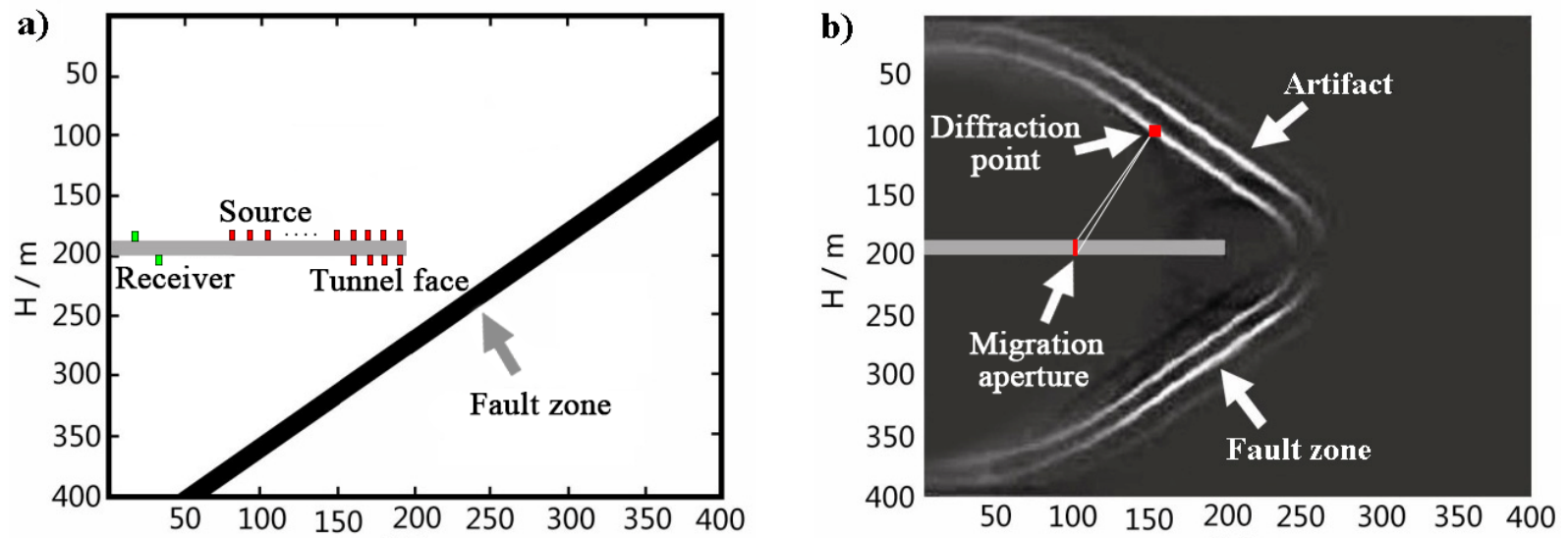

Fig. 1 Advanced migration imaging.

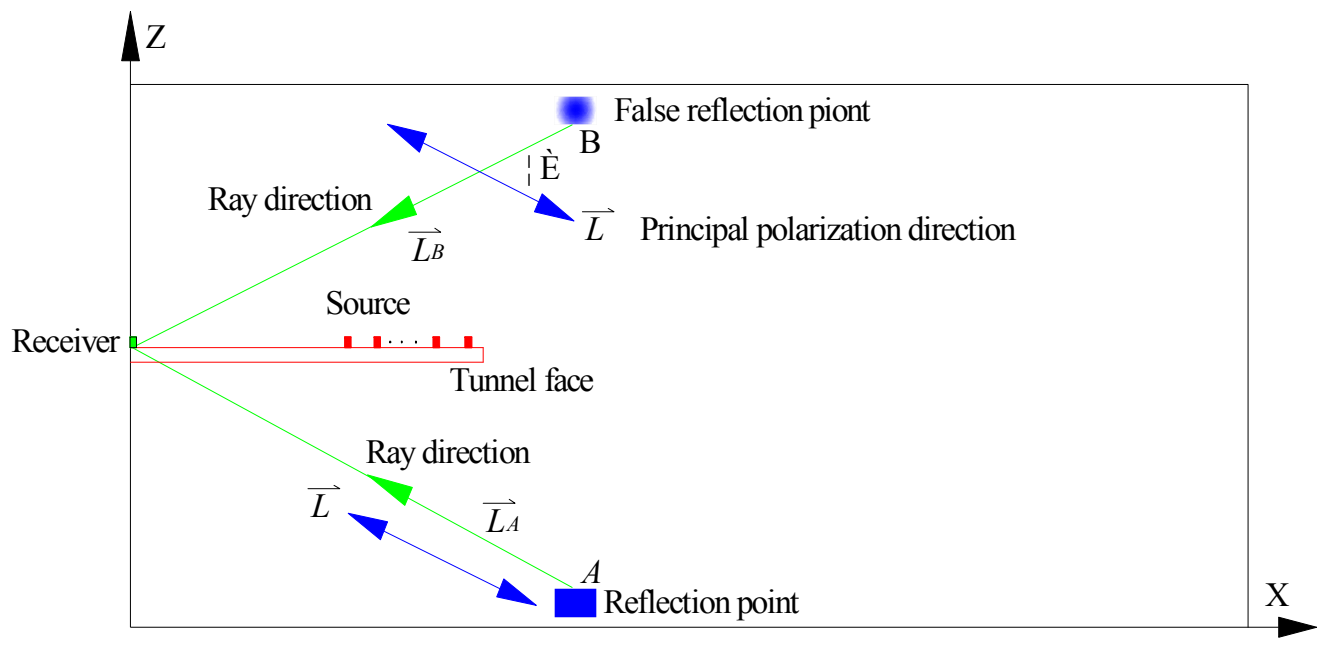

Fig. 2 Polarization migration imaging of PP reflection.

\section{THEORY OF POLARIZATION MIGRATION PRINCIPLE}

Figure 2 is a $\mathrm{P}$-wave imaging in homogeneous media. Point A represents any reflection point in the space, while point B is its symmetrical false reflection point with the seismic line as the symmetry axis. When PP reflection propagates from reflected point A to a receiver, its principal energy path trajectory can be denoted as ray direction $\vec{L}_{A}$. When the receiver receives reflected information from point $A$, its particle vibration direction is the principal polarization direction $\vec{L}$. Because $\mathrm{A}$ is the actual imaging point, the direction of $\vec{L}_{A}$ is consistent with that of $\vec{L}$. Accordingly, the angle between the two directions is $0^{\circ}$ and its cosine value is 1 . The ray direction from the false imaging point $\mathrm{B}$ to the receiver is denoted as $\overrightarrow{L_{B}}$, and it will form an acute angle $\theta$ with the principal polarization direction $\vec{L}$, and its cosine value as $\cos \theta$. Since $\cos \theta$ has an apparent difference from the cosine value of the angle between $\vec{L}$ and $\vec{L}_{A}$, we can use a weighted function of $\cos \theta$ to identify the false reflected point and suppress its amplitude value during the imaging process to achieve the migration of the actual reflected point. This method is called polarization migration, owing to the introduction of weighted functions related to the principal polarization direction during the prestack migration process.

Polarization migration can be used to image in small migration apertures and solve imaging problems of symmetrical artifact caused by limited imaging condition. In Figure 2, sources and receivers are located on the same horizontal straight line, the seismic line. Under this circumstance, migration aperture is zero, which makes accurate imaging difficult.

The process of polarization migration mainly involves prestack migration and polarization analysis related to the principal polarization direction, which will be elaborated in the following sections.

\section{POLARIZATION ANALYSIS}

The particle movement trajectory of, e.g., a PP reflection can be described by an ellipsoid, the longest axis of which is the principal polarization direction. The principal polarization of $3 \mathrm{C}$ seismic data is analyzed by determining the eigenvectors of a covariance matrix. 
The amplitude value of each sampling point can be recorded by three components $X, Y$, and $Z$, which can be regarded as the three coordinate values in a spatial coordinate system. Hence, a sampling point can be positioned in a $3 \mathrm{D}$ orthogonal coordinate system as $\left(X_{i}, Y_{i}, Z_{i}\right)$. With $X_{i}, Y_{i}, Z_{i}$ denoting the amplitude values in three directions, respectively, at any sampling point in a time window $\left(t_{1}, t_{2}\right)$, when the number of sampling points is $\mathrm{M}$, the average values of the three components for a receiver point are, respectively:

$N_{x}=\frac{1}{M} \sum_{i=M_{1}}^{M_{2}} X_{i}, \quad N_{y}=\frac{1}{M} \sum_{i=M_{1}}^{M_{2}} Y_{i}, N_{z}=\frac{1}{M} \sum_{i=M_{1}}^{M_{2}} Z_{i}$

where $\left(M_{2}-M_{1}\right) * \Delta \mathrm{t}=\mathrm{t}_{2}-\mathrm{t}_{1}, M=M_{2}-M_{1}+1$.

A covariance matrix can be obtained:

$$
\left[\begin{array}{l}
\sum_{i=M_{1}}^{M_{2}}\left(X_{i}-N_{x}\right)\left(X_{i}-N_{x}\right), \sum_{i=M_{1}}^{M_{2}}\left(X_{i}-N_{x}\right)\left(Y_{i}-N_{y}\right), \sum_{i=M_{1}}^{M_{2}}\left(X_{i}-N_{x}\right)\left(Z_{i}-N_{z}\right) \\
\sum_{i=M_{1}}^{M_{2}}\left(Y_{i}-N_{y}\right)\left(X_{i}-N_{x}\right), \sum_{i=M_{1}}^{M_{2}}\left(Y_{i}-N_{y}\right)\left(Y_{i}-N_{y}\right), \sum_{i=M_{1}}^{M_{2}}\left(Y_{i}-N_{y}\right)\left(Z_{i}-N_{z}\right) \\
\sum_{i=M_{1}}^{M_{2}}\left(Z_{i}-N_{z}\right)\left(X_{i}-N_{x}\right), \sum_{i=M_{1}}^{M_{2}}\left(Z_{i}-N_{z}\right)\left(Y_{i}-N_{y}\right), \sum_{i=M_{1}}^{M_{2}}\left(Z_{i}-N_{z}\right)\left(Z_{i}-N_{z}\right)
\end{array}\right]
$$

The three eigenvalues $\lambda_{1}, \lambda_{2}$ and $\lambda_{3}$ of the above covariance matrix correspond to the long, medium and short axes of the ellipsoid composed by particle vibration trajectory respectively when $\lambda_{1}>\lambda_{2}>\lambda_{3}$. The eigenvectors corresponding to the three eigenvalues $\lambda_{1}, \lambda_{2}$ and $\lambda_{3}$ represent directions of the long, medium and short axes of the elliptic trajectory, respectively.

In the spatial orthogonal coordinate system, we assume the angle between the principal eigenvector V1 with, respectively, $\mathrm{X}$ axis, $\mathrm{Y}$ axis, and $\mathrm{Z}$ axis as $\alpha_{1}, \beta_{1}, \gamma_{1}$. This equation can be obtained:

$\left\{\begin{array}{l}V_{x}=\cos \alpha_{1}(t) \\ V_{y}=\cos \beta_{1}(t) \\ V_{z}=\cos \gamma_{1}(t)\end{array}\right.$

where $V_{x}^{2}+V_{y}^{2}+V_{z}^{2}=1$, and the principal eigenvector represents the principal polarization direction.

\section{POLARIZATION MIGRATION}

Kirchhoff prestack depth migration is often expressed as a diffraction integral in a scalar wave field. On the basis of Kirchhoff migration, a weighted function is introduced into polarization migration, and a migration formula can be defined as:

$U(p)=\frac{-1}{2 \pi} \iint_{A} k(\mathrm{p}, \mathbf{x}) \dot{u}\left(\mathbf{x}, t_{S}+t_{R}\right) d \mathbf{x}$

In the above equation, $k(p, x)=\cos ^{q} \theta, k(p, x)$ is a modulation function of amplitude value for any imaging point during $\mathrm{P}$-wave imaging. The acute angle $\theta$ represents the angle between the ray direction from any imaging point and the principal polarization direction. The $q$ in $k(p, x)$ ranges between 1 and 10 .

Taking the $3 \mathrm{C}$ seismic wave vector characteristics into account, the polarization migration technique suppresses false imaging by using the principal polarization vector on the basis of an amplitude value scalar stack. The specific flow chart during the calculation process is shown in Figure 3.

The principal polarization direction can be calculated through a covariance matrix, which has a significant impact on the migration result. The key of this calculation is to determine the time window length $\left(t_{1}, t_{2}\right)$. If the selected time period is too short, the consistency of the seismic signal is likely to be ignored. If the selected time window is too long, other interference signals will cause errors in polarization analysis. In this paper, we propose the S-transformation time-frequency analysis method to determine time window length. Through time-frequency analysis, dominant frequency $f$ at time $t$ (corresponding to the travel time from the imaging point) could be determined. The average period at time $\mathrm{t}$ is $1 / f$, so the time window length should be $1 / f$. Because this method is based on S-transformation multi-resolution analysis, it is more reasonable to determine time window length at any time. 


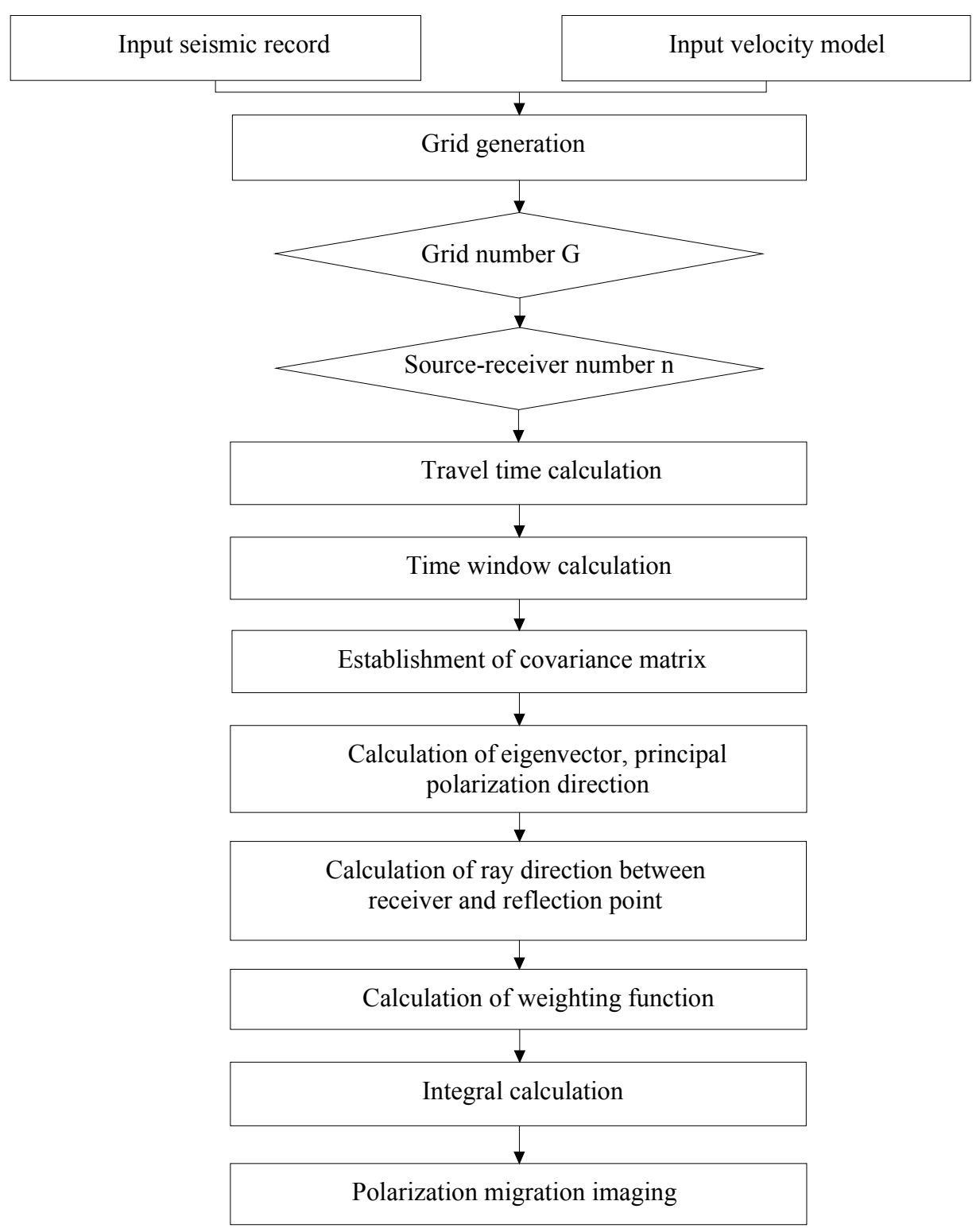

Fig. 3 Flow chart of Polarization migration imaging.

\section{NUMERICAL SIMULATION}

The model of three abnormal interfaces with the same trend was established to analyze the imaging result of polarization migration, whose parameters are shown in Table 1. In this simulation, grid size is $400 \mathrm{~m} \times 400 \mathrm{~m}$ with the spacing $\Delta \mathrm{x}=0.5 \mathrm{~m}, \Delta \mathrm{z}=0.5 \mathrm{~m}$. The sampling interval is $\Delta \mathrm{t}=0.05 \mathrm{~ms}$. Ricker wavelet frequency is set as $400 \mathrm{~Hz}$ (Gong et al., 2010). To simulate two components $\mathrm{X}$ and $\mathrm{Z}$ based on acoustic wave equation, we can obtain seismic data of the two components within $120 \mathrm{~ms}$ (seen in Figure 4). According to kinematic characteristics of seismic data, four kinds of waves have been received, namely, A the direct $\mathrm{P}$-wave, $\mathbf{B}$ the $\mathrm{P}$-wave reflected from interface R1, $\mathbf{C}$ the P-wave reflected from interface R2, and $\mathbf{D}$ the P-wave reflected from interface R3. While analyzing the seismic signals of $\mathbf{B}, \mathbf{C}$, and $\mathbf{D}$, the components $X, Z, Z$ are synthetized as 3 component signals (polarization analysis in this paper is exclusive for $3 \mathrm{C}$ signals).

The principal polarization direction can be calculated by using polarization analysis shown above. Since the actual signals are components $\mathrm{X}$ and $\mathrm{Z}$, the principal polarization direction is projected in

Table 1 Model parameter.

\begin{tabular}{|c|c|c|c|c|}
\hline No & P-wave velocity $(\mathrm{m} / \mathrm{s})$ & Interface & Front distance $(\mathrm{m})$ & Dip (degree) \\
\hline 1 & 3800 & & & \\
\hline 2 & 4100 & R1 & 75 & 33 \\
\hline 3 & 4500 & R2 & 160 & 53 \\
\hline 4 & 5000 & R3 & 227 & 80 \\
\hline
\end{tabular}




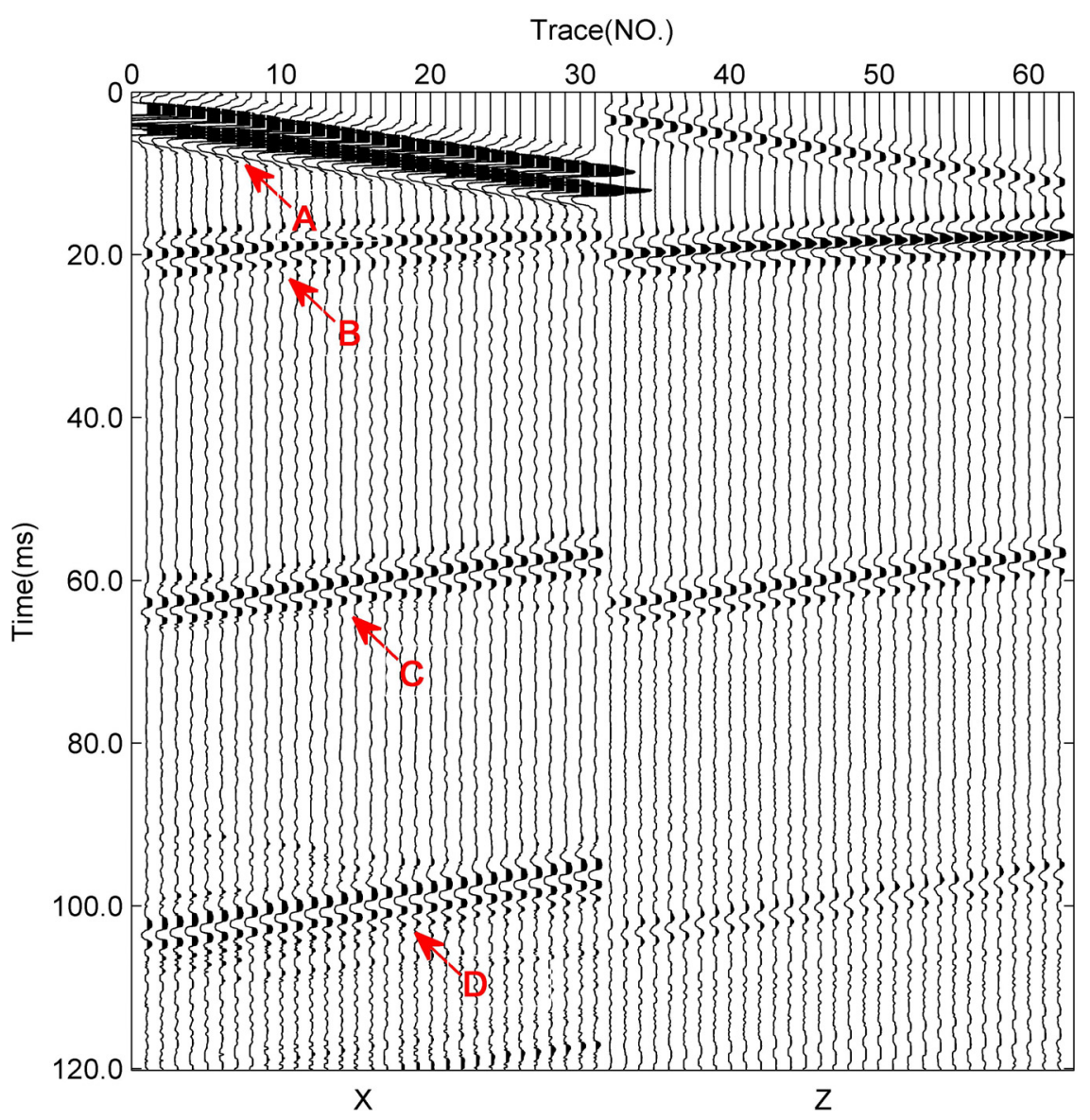

Fig. 4 Synthetic data of the model.

the $\mathrm{XZ}$ plane. In the process of polarization analysis, the time window can be calculated by the S-transformation time-frequency analysis method. It can be seen from Figure 5 that the dominant frequencies at $20.5 \mathrm{~ms}, 63 \mathrm{~ms}$, and $103.5 \mathrm{~ms}$ is $400 \mathrm{~Hz}$, their corresponding period lasting $2.5 \mathrm{~ms}$. Figure 6 shows the spatial trajectories and their projections in the XZ plane of minimum offset trace when the time windows are $19.2 \sim 21.7 \mathrm{~ms}, 61.8 \sim 64.3 \mathrm{~ms}$, and $102.4 \sim 104.9 \mathrm{~ms}$, respectively.

The polarization migration result in Figure 7 (a) shows that the distances of the three abnormal interfaces R1, R2, and R3 from the zero point are, respectively, $75 \mathrm{~m}, 160 \mathrm{~m}$, and $227 \mathrm{~m}$, with corresponding dip of $33^{\circ}, 53^{\circ}$, and $80^{\circ}$. Calculated results are consistent with the designed model, including effective imaging of dips and trends. However, reverse-time migration results in Figure 7(b) show that three artifacts are noticeable, which leads to low direction resolution. The cause of this is that reverse-time migration is affected by the linear observational system with zero migration aperture in the roadway.

Therefore, energy convergence is improved by using polarization migration instead of reverse-time migration. With the principal polarization direction,

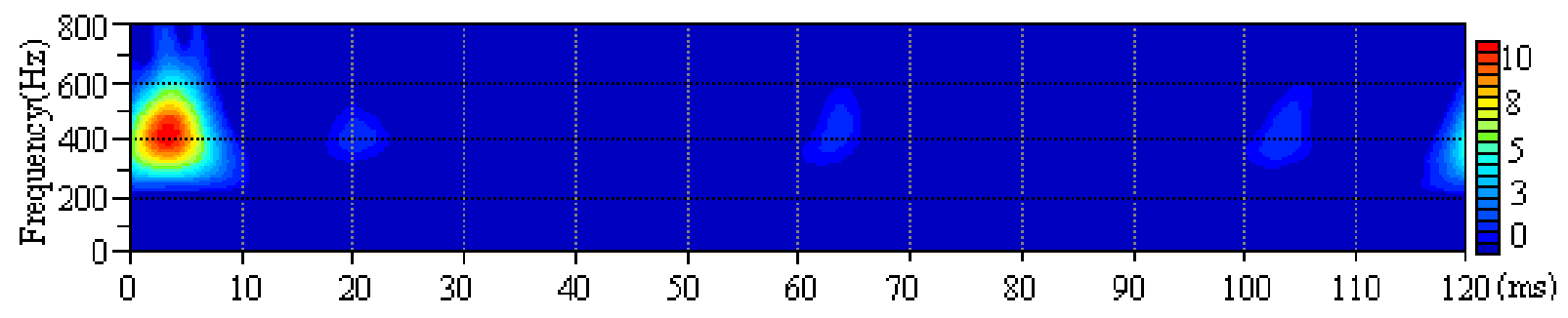

Fig. 5 Time-frequency analysis of X-component seismic signal of minimum offset trace. 

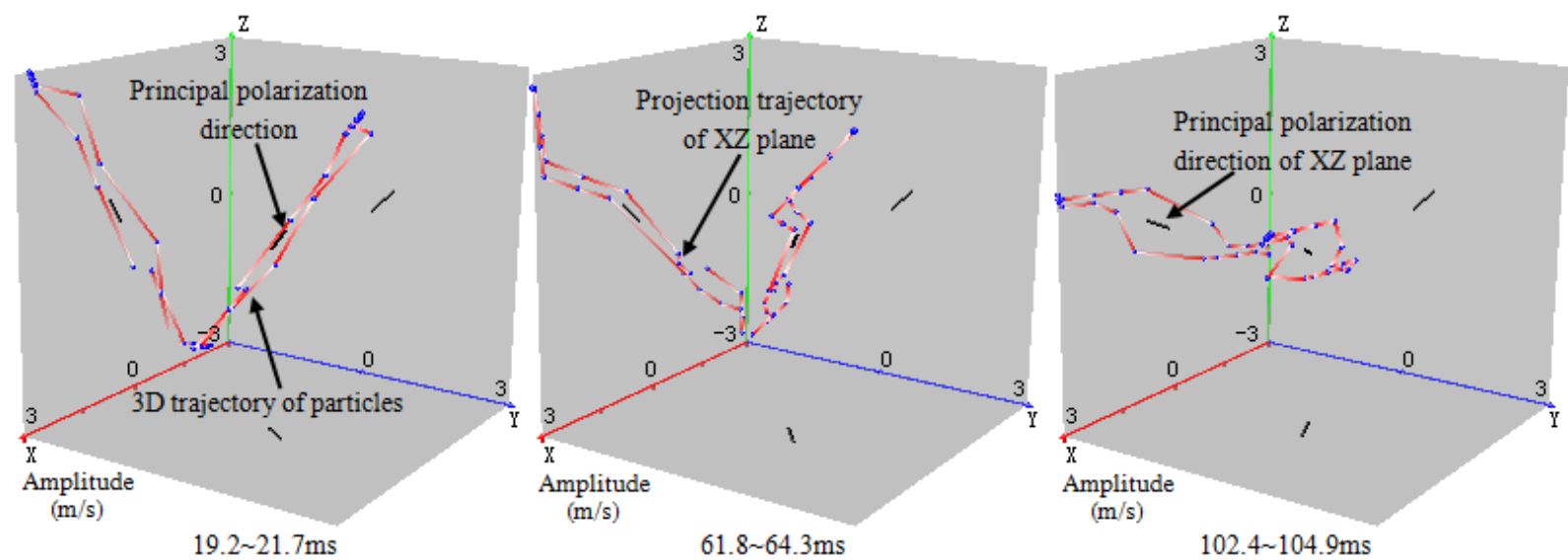

Fig. 6 Polarization trajectories of the $3 \mathrm{C}$ seismic signal of minimum offset trace.

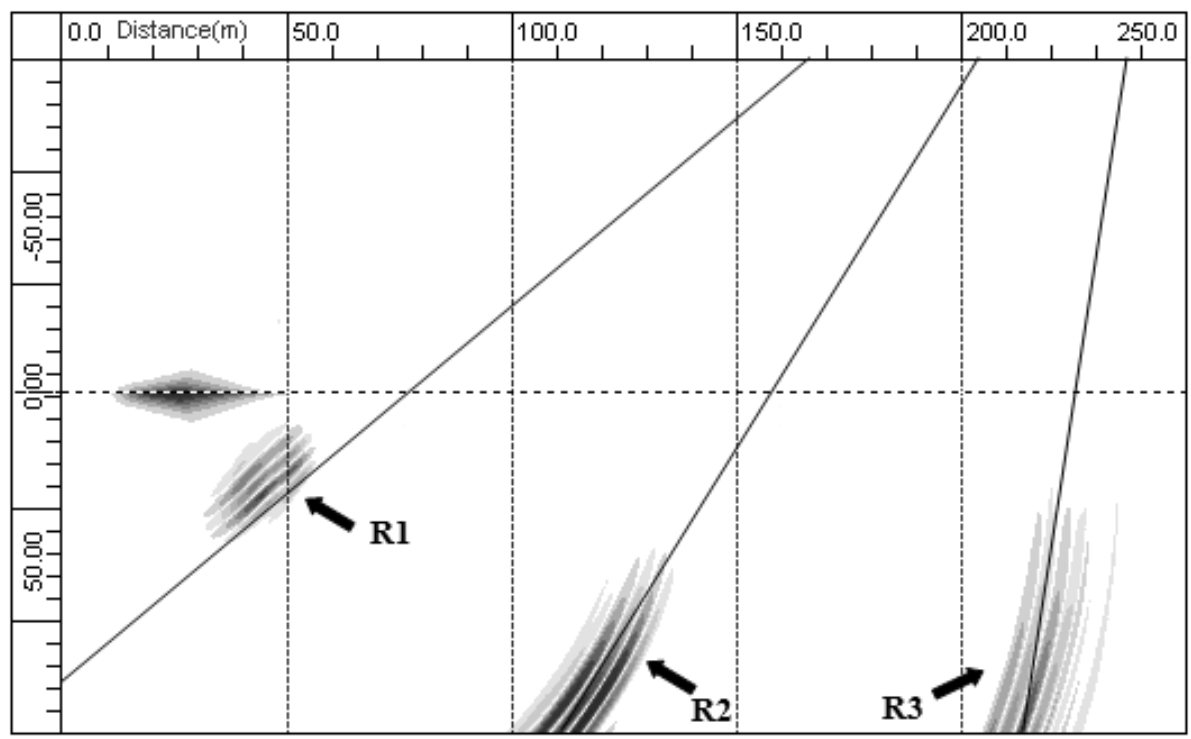

(a) Polarization migration

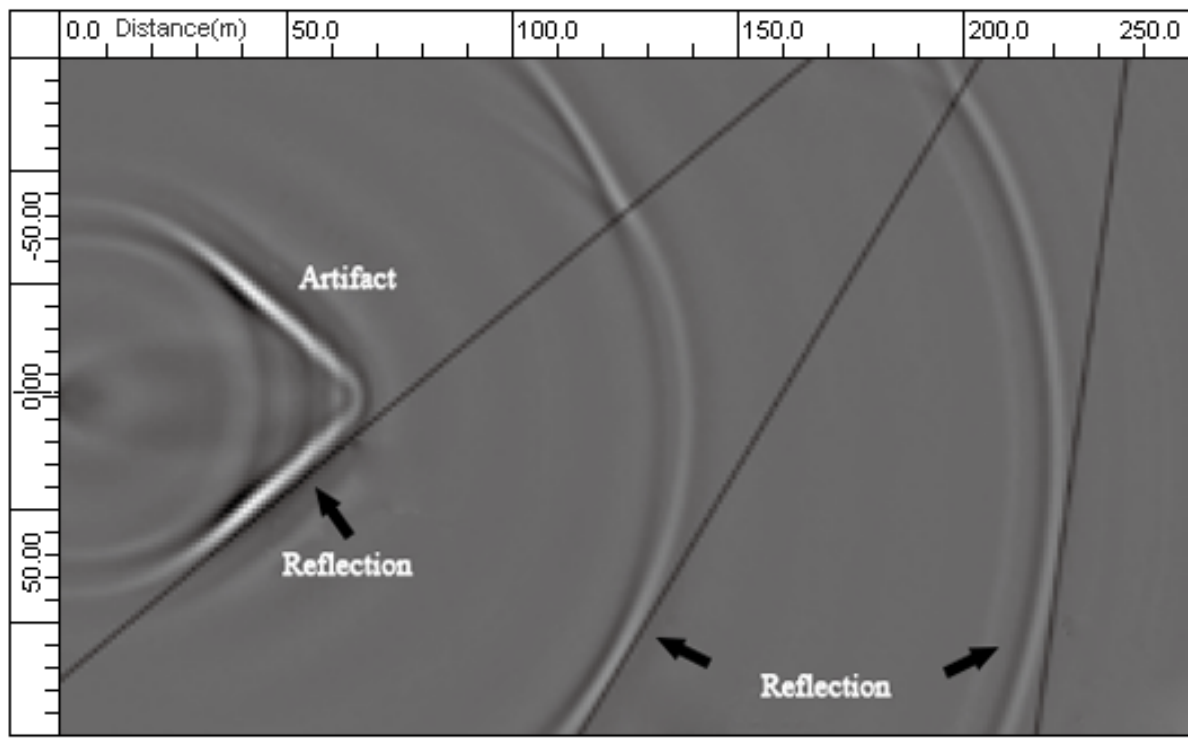

(b) Reverse-time migration.

Fig. 7 Imaging comparison with two migration methods. 


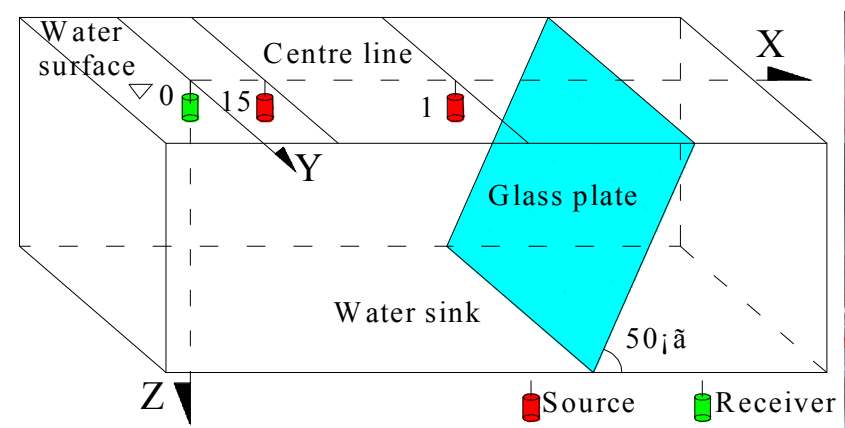

(a) Model construction

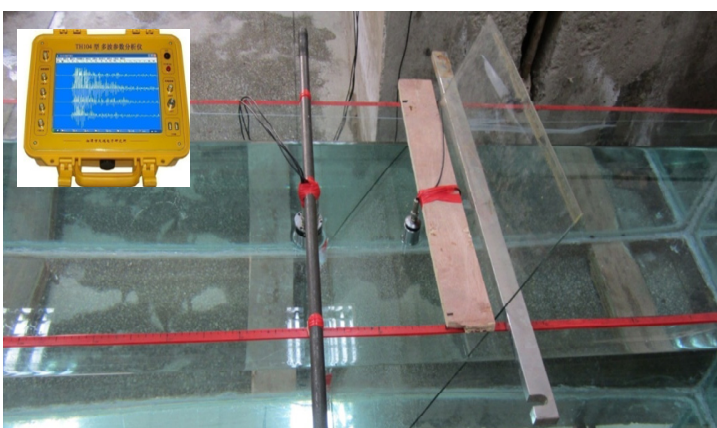

(b) Actual object

Fig. 8 Water sink model.

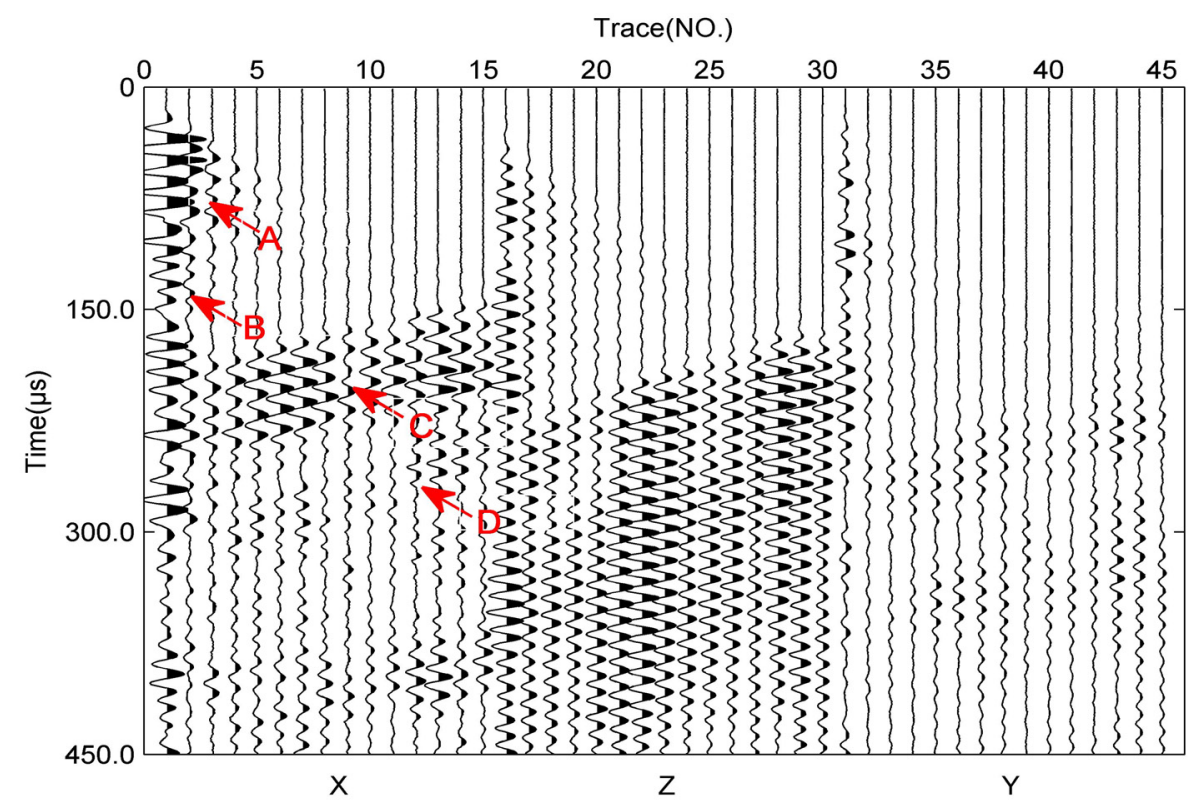

Fig. 9 Synthetic data of water sink model.

the abnormal interfaces can be located accurately with polarization migration under small aperture.

\section{PHYSICAL SIMULATION}

To verify the imaging effect of polarization migration in a physical simulation, a water sink model was established with the size of $2.6 \mathrm{~m} \times 0.8 \mathrm{~m} \times 0.8 \mathrm{~m}$ (illustrated in Figure 8). According to similarity criterion of seismic wave propagation, the ratio of space length, velocity, frequency, and sampling interval for the model to their actual counterparts are, respectively, 1:100, 1:1, 100:1, 1:100. A $100 \mathrm{KHz}$ single component $\mathrm{P}$-wave piezoelectric transducer was used as the source, and a $100 \mathrm{KHz} 3 \mathrm{C}$ piezoelectric transducer was used as the receiver. A TH104 wave parameter analyzer was used as the data-acquisition instrument.

The $3 \mathrm{C}$ original signals come from water sink model. The smallest offset is $0.05 \mathrm{~m}$, and the shot interval is $0.01 \mathrm{~m}$; the excitation was completed
15 times. The sampling frequency is $1 \mathrm{MHz}$ with 1024 sampling points; the selected time length is $450 \mu \mathrm{s}$.

The experiment is designed to avoid the interference of reflected waves from the sink sides and bottom. Hence, the original signals are mainly direct waves and reflected waves from the glass. From the original signal of component $\mathrm{X}$ in Figure 9, two groups of direct waves can be observed: the direct Pwaves $\mathbf{A}$ and $\mathbf{B}$. Because a transducer can produce several shock excitations, there will emerge other groups of reflected waves (not allowing for subsequent multiple reflected waves, because of imaging on a single interface), which are reflected Pwaves $\mathbf{C}$ and $\mathbf{D}$ (seen in Figure 9). The interval between the 1 st and 15 th trace for reflected P-wave $\mathbf{C}$ is within $150 \sim 240 \mu s$, while the interval for reflected P-wave $\mathbf{D}$ is within $240 \sim 330 \mu s$. The two groups of reflection are all characterized by negative apparent velocity characteristics. 


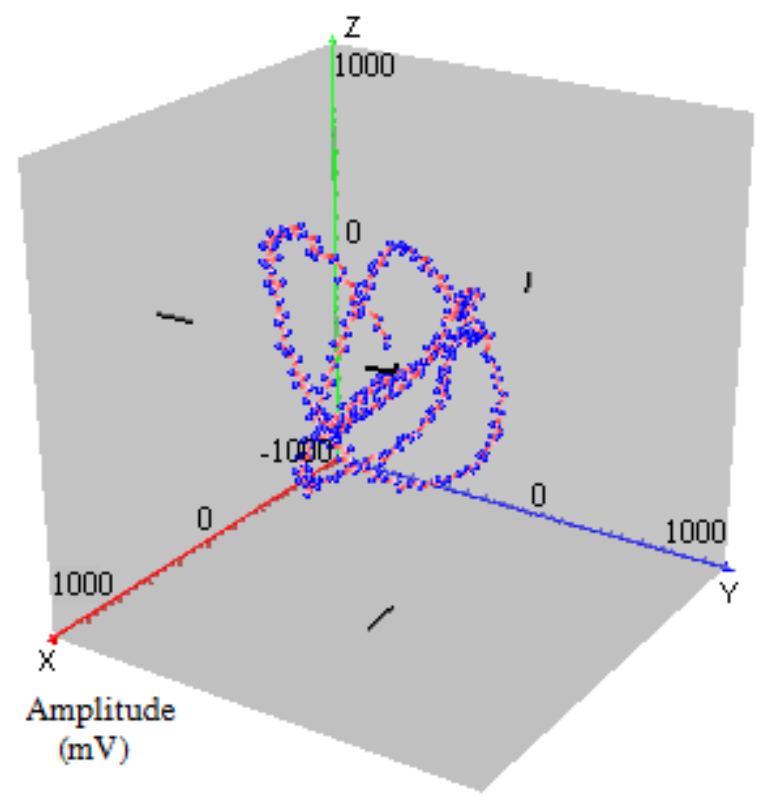

Fig. 10 Polarization trajectorys of $\mathrm{C}$ PP reflection of No.15 shot.

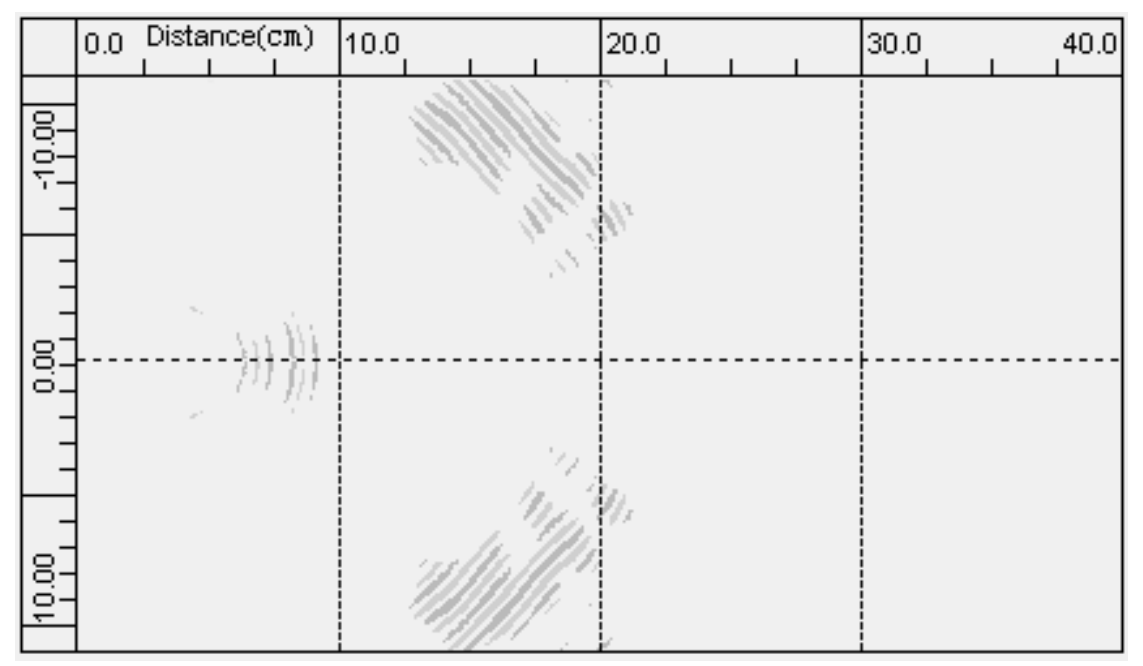

Fig. 11 Prestack diffraction of water sink model.

As for the component signals $\mathrm{X}, \mathrm{Y}$, and $\mathrm{Z}$, the reflected energy of component $\mathrm{X}$ is apparently stronger than those of component $\mathrm{Y}$ and $\mathrm{Z}$, with $\mathrm{Y}$ being the weakest. We selected the $3 \mathrm{C}$ signal of the 15th reflected wave to draw its trajectory (Fig. 10). The angle between the projection of the principal polarization direction in the $\mathrm{XZ}$ plane and the $\mathrm{X}$ axis is $40^{\circ}$, an acute angle. The principal polarization direction is parallel with the wave propagating direction (the ray direction, represented by a yellow arrow in the $X Z$ plane), parallel with the $X$-axis in the $\mathrm{XY}$ plane, and parallel with the Z-axis in the YZ plane. Thus, it can be deduced that the principal energy is in the XZ plane. Those features conform with the propagating characteristic of the P-wave.
Having filtered the subsequent signal of reflected wave $\mathbf{D}$, prestack diffraction migration can be carried out in the XZ plane based on a $1250 \mathrm{~m} / \mathrm{s}$ P-wave homogeneous velocity model, which leads to false artifact imaging (as seen in Figure 11). As a result, the anomaly cannot be identified efficiently. Thus, we perform polarization migration. It can be found in Figure 12 that the dip of the strong power abnormal interface $\mathrm{R} 1$ is $50^{\circ}$, while interface $\mathrm{R} 1$ cuts the water face (the medial axis) at the point of $0.23 \mathrm{~m}$ (the point of $0 \mathrm{~m}$ is set at the location of the $3 \mathrm{C}$ receiving transducer). The dip, trend, and spatial position of interface R1 are consistent with glass layout parameters of the sink model. 


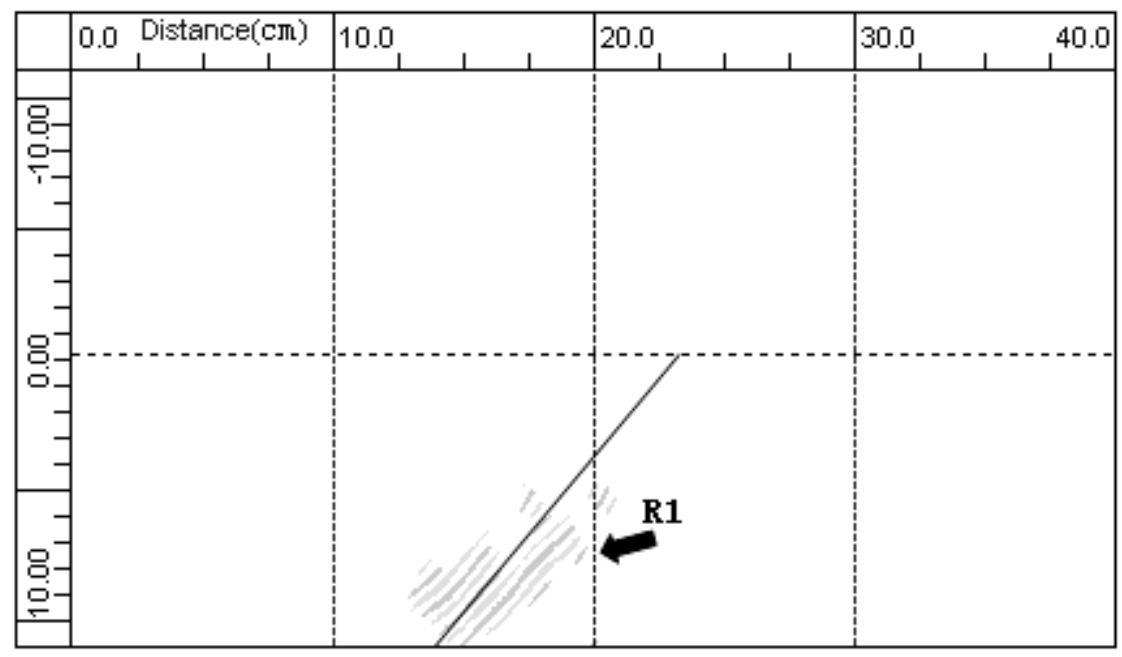

(a) 2D Polarization migration

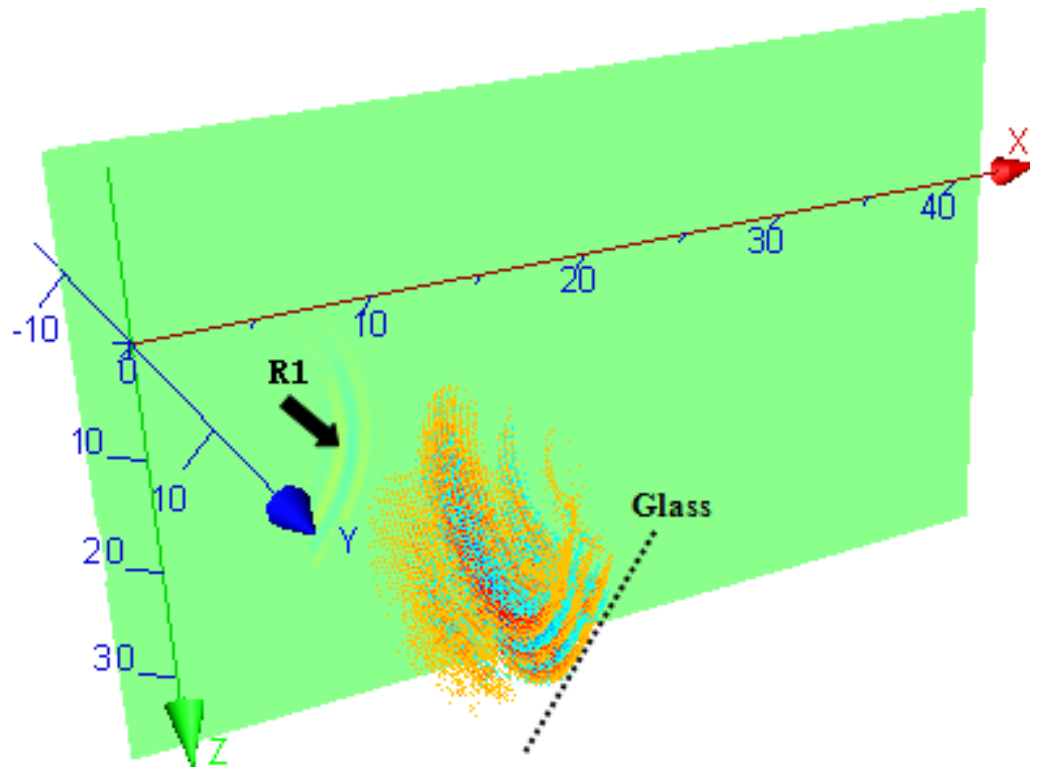

(b) 3D Polarization migration

Fig. 12 Polarization migration of water sink model.

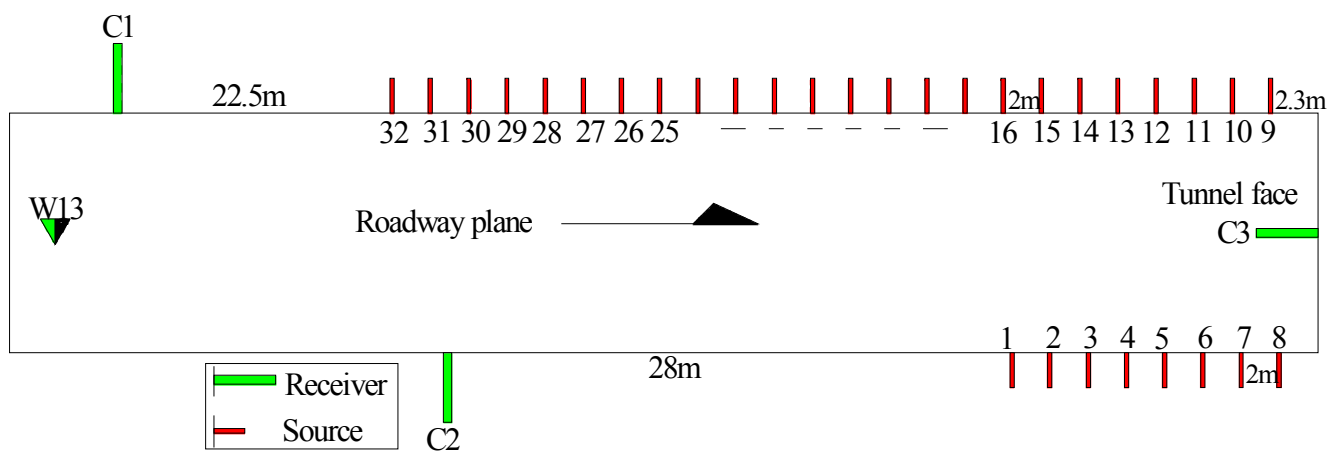

Fig. 13 Field layout diagram. 


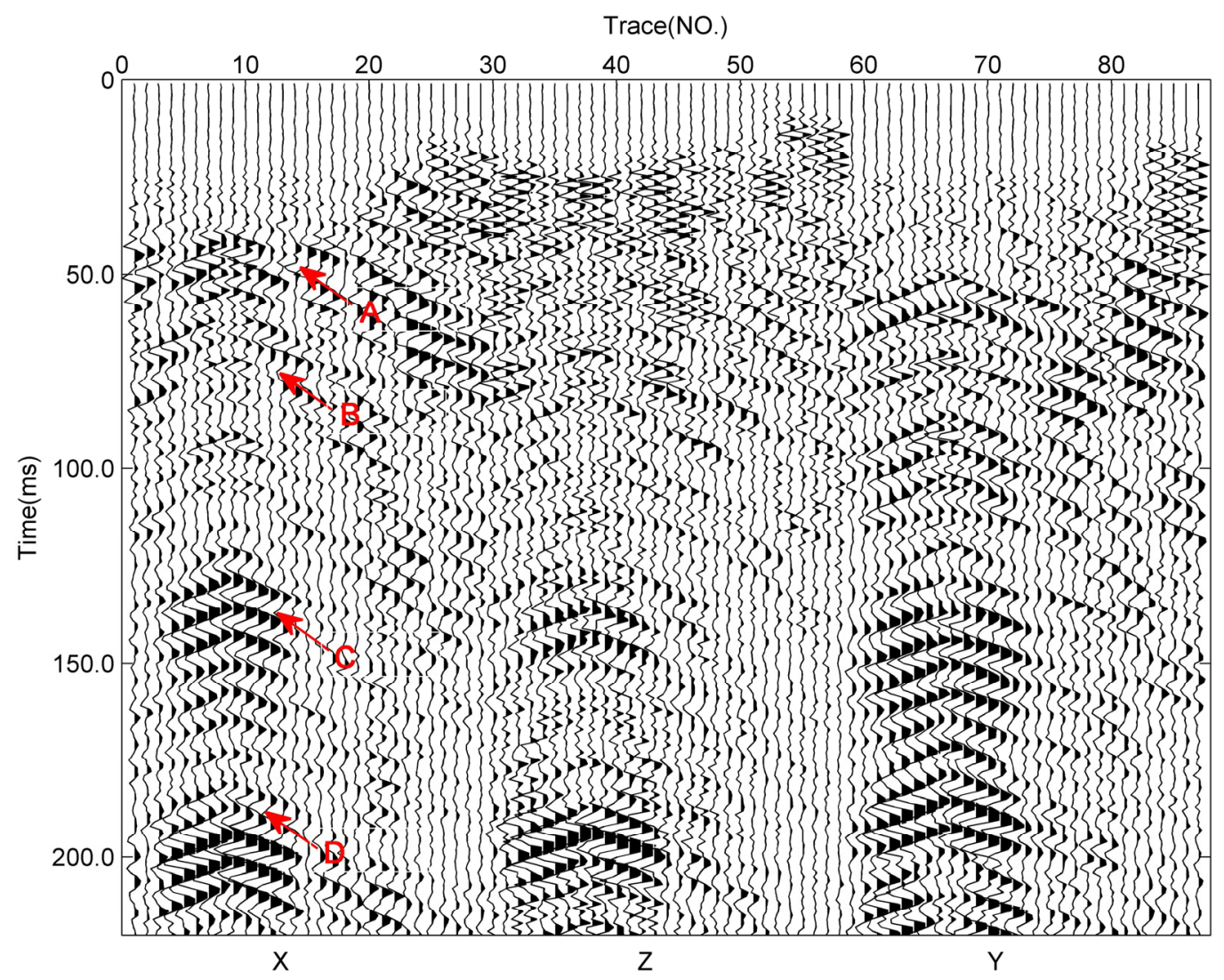

Fig. 14 Reflected waves extracted from the field data.

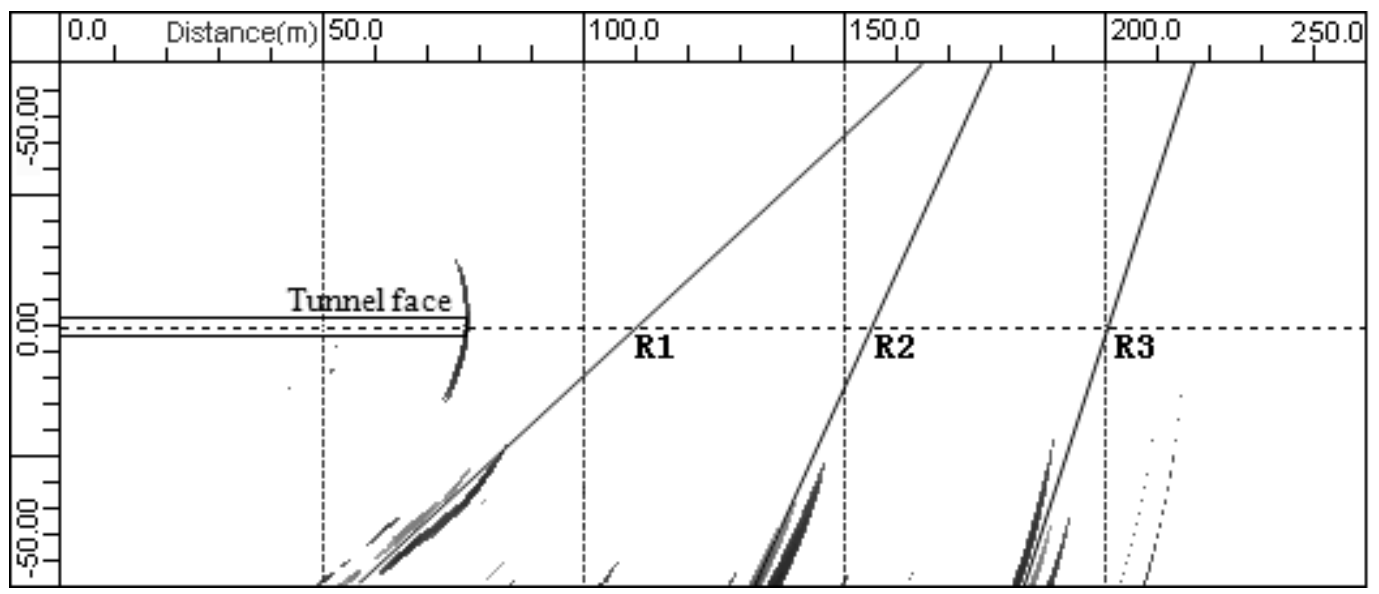

Fig. 15 Polarization migration profile with P-waves.

\section{FIELD APPLICATION}

Fieldwork was carried out at the No.21 return airway of the Longdong coal mine in Jiangsu, China. $\mathrm{W} 13+81.3 \mathrm{~m}$ was set as zero point for the layout of the observation system (Fig. 13). Apart from 3 misfires, 29 groups of $3 \mathrm{C}$ seismic data were obtained. After pretreatment, the reflected signal can be acquired through a 2D Fourier transformer and Radon transform for space filtering (seen in Figure 14). Four groups of negative apparent velocity events can be identified clearly in the seismic profile. The velocity model was established based on superimposed energy maximization method, and a migration imaging profile was obtained by analyzing the P-waves signal of component X (Fig. 15). From the profile, we can find three abnormal interfaces, R1, R2, and R3 at, respectively, $37 \mathrm{~m}, 76 \mathrm{~m}, 121 \mathrm{~m}$ ahead of the tunnel face, dipping at $43^{\circ}, 65^{\circ}, 72^{\circ}$, and trending to the roadway.

Figure 16 shows that the $37 \mathrm{~m}$ point is a lithological interface changing from gritstone to limestone; the $76 \mathrm{~m}$ point is lithological interface changing from sandy mudstone to gritstone. The F6 fault is located at the $120 \mathrm{~m}$ point, the fault throw is $40 \mathrm{~m}$, and the dip is 


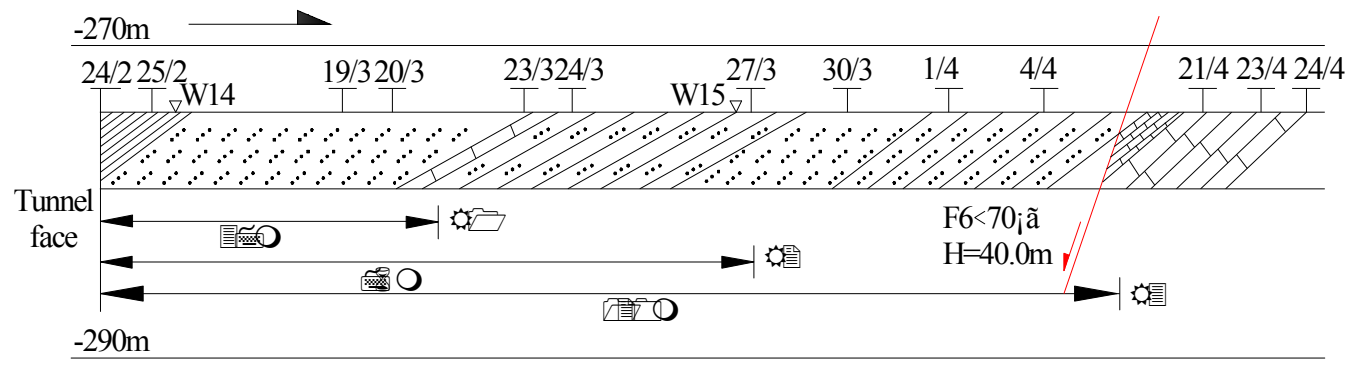

Fig. 16 Measured section after excavating.

$70^{\circ}$. Analysis based on detection and validation data shows that the detection distance error between the F6 fault and the R3 interface is $1 \mathrm{~m}$, and the dip error is $2^{\circ}$. The interfaces of both $\mathrm{R} 1$ and $\mathrm{R} 2$ coincide with the lithological changing zone of the actual excavated information.

\section{CONCLUSIONS}

From the perspective of real-time polarization analysis of multi-component seismic signals, in view of the angle between ray direction and principal polarization direction differences of true and false reflection points, we introduced a principal polarization direction factor. We then established a weighted function of the factor, and integrated the function into the migration calculation. Finally, we proposed the polarization migration algorithm, which takes into account the vector characteristic of seismic waves.

The numerical simulation has been carried out for the three abnormal interface models. We analyzed the polarization characteristics of P-waves and adopted S-transformation time-frequency analysis method for selection of time window length. The comparison of polarization migration and reverse-time migration demonstrates that the former features have better energy convergence and a higher directional resolution. Therefore, polarization migration can be used to solve the symmetrical imaging artifacts problem effectively, and it can be applied in the roadway linear observing system. The sink model experiment and the field experiment indicates that polarization migration can define the location and occurrence of interfaces.

\section{ACKNOWLEDGEMENTS}

This research has been performed under the Joint Funding Project of National Natural Science Foundation and ShenHua Group Corporation Ltd (No. U1261202), National Natural Science Foundation Project (No. 51374203, 51323004, 41474122). A Project Funded by the Priority Academic Program Development of Jiangsu Higher Education Institutions. We would like to address many thanks to the anonymous reviewers for their very careful reading and issuing a number of comments, which helped to improve the paper.

\section{REFERENCES}

Bohlen, T., Lorang, U., Rabbel, W., Müller, C., Giese, R., Lüth, S. and Jetschny, S.: 2007, Rayleigh-to-shear wave conversion at the tunnel face from 3D-FD. Geophysics, 72, No. 6, 67-79. DOI: $10.1190 / 1.2785978$

Borm, G., Giese, R., Otto, P., Dickmann, Th. and Amberg, F.: 2001, Integrated seismic imaging system for geological prediction ahead in underground construction. Proceedings-Rapid Excavation and Tunneling Conference, 263-271.

Busygin, B. and Nikulin, S.: 2013, Predicting methane accumulation in the Donetsk coal basin (Ukraine) on the basis of geological, geophysical and space data. Energy Efficiency Improvement of Geotechnical Systems - Proceedings of the International Forum on Energy Efficiency, 161-167.

Chang, X., Liu, Y.K. and Gui, Z.X.: 2006, Zero-offset reverse time migration for prediction ahead of tunnel face. Chinese Journal of Geophysics, 49, No. 5, 14821488, (in Chinese).

Cheng, J.L., Li,F., Peng, S.P., and Sun, X.Y.: 2014, Research progress and development direction in mine roadway working face using geophysical methods. Journal of China Coal Society, 39, No. 8, 1742-1750. (in Chinese). DOI: 10. 13225/ j. cnki. jccs. 2014. 9007

Esaki, T., Djamaluddin, I. and Mitani, Y.: 2008, A GISbased prediction method to evaluate subsidenceinduced damage from coal mining beneath a reservoir, Kyushu, Japan. Quarterly Journal of Engineering Geology and Hydrogeology, 41, No. 3, 381-392. DOI: $10.1144 / 1470-9236 / 07-217$

Essen, K., Bohlen, T., Friederich, W. and Meier, T.: 2007, Modelling of Rayleigh-type seam waves in disturbed coal seams and around a coal mine roadway. Geophysical Journal International, 170, No. 2, 511526. DOI: 10.1111/J.1365-246X.2007.03436.x

Gong, X.B., Han, L.G. and Niu, J.J.: 2010, Combined migration velocity model-building and its application in tunnel seismic prediction. Applied Geophysics, 7, No. 3, 265-271. DOI: 10.1007/s11770-010-0251-3

Inazaki, T., Isahaki, H., Kawahura, S., Kurahashi, T. and Hayashi, H.: 1999, Stepwise application of horizontal seismic profiling for tunnel prediction ahead of the face. Leading Edge, 18, No. 12, 1429-1431. 
Islam, M.R. and Shinjo, R.: 2009, Mining-induced fault reactivation associated with the main conveyor belt roadway and safety of the Barapukuria Coal Mine in Bangladesh: Constraints from BEM simulations. International Journal of Coal Geology, 79, No. 4, 115130. DOI: $10.1016 /$ j.coal.2009.06.007

Kabiesz, J.: 2006, Effect of the form of data on the quality of mine tremors hazard forecasting using neural networks. Geotechnical and Geological Engineering, 24, No. 5, 1131-1147. DOI: 10.1007/s10706-005-1136-8

Li, L.C., Yang, T.H., Liang, Z.Z., Zhu, W.C. and Tang, C.N.: 2011, Numerical investigation of groundwater outbursts near faults in underground coal mines. International Journal of Coal Geology, 85, No. 3, 276288. DOI: $10.1016 /$ j.coal.2010.12.006

Liu, Y.Z. and Mei, R.W.: 2011, Advantages of TGP advance geology prediction technology in tunnels. Tunnel Construction, 31, No. 1, 21-32, (in Chinese).

Lüth, S., Buske, S., Giese, R. and Goertz, A.: 2005, Fresnel volume migration of multicomponent data. Geophysics, 70, No. 6, 121-129. DOI: $10.1190 / 1.2127114$

Sattel, G., Sander, B., Amberg, F. and Kashiwa, T.: 1996, Predicting ahead of the face. Tunnels and Tunnelling International, 28, No. 4, 24-30.
Shen, H.Y., Li, Q,C., Feng, H., Zhang, P. and Shao, G.Z.: 2008, Study on leading tunnel reflection seismic prediction. Journal of the China Railway Society, 30, No. 6, 75-81, (in Chinese).

Wang, B., Liu, S.D., Liu, J., Huang, L.Y. and Zhao, L.G.: 2011, Advanced prediction for multiple disaster sources of laneway under complicated geological conditions. Mining Science and Technology, 21, No. 5, 749-754. DOI: 10.1016/j.mstc.2011.03.001

Wang, B., Liu, S.D., Lu, T. and Sun, H.L.: 2014, Coal seam thickness detection in mine roadway by using advanced prediction method. Electronic Journal of Geotechnical Engineering. 21, No. 5, 4753-4762.

Zeng, Z.H.: 1994, Prediction ahead of the tunnel face by the seismic reflection methods. Chinese Journal of Geophysics, 37, No. 2, 268-271, (in Chinese).

Zhang, R.L. and Lan, S.L.: 2013, The application of a coupled artificial neural network and fault tree analysis model to predict coal and gas outbursts. International Journal of Coal Geology, 84, No. 2, 141152. DOI: $10.1016 /$ j.coal.2010.09.004

Zhao, Y.G., Jiang, H. and Zhao, X.P.: 2006, Tunnel seismic tomography method for geological prediction and its application. Applied Geophysics, 3, No. 2, 69-74. 